\title{
ASSESSMENT OF TEACHING PRACTICES ON MATHEMATICS FOR STUDENTS IN QATAR
}

\author{
Ali Rashash R Alzahrani, Elizabeth Stojanovski, and Peter Howley \\ University of Newcastle, Newcastle, Australia \\ alirashashr.alzahrani@uon.edu.au
}

While understanding statistics is essential, teaching this content is challenging. There is an increased need to improve teaching practices to achieve positive outcomes in mathematics and statistics education. Improved mathematics teaching in schools is essential to motivate more students to undertake Science, Technology, Engineering and Mathematics (STEM)-related courses at University given the demand for STEM skills. Data on school students in Qatar was analysed to compare the effectiveness of different teaching methods on mathematics exam performance. Students performed better when cognitive-based approaches to teaching were used. Findings from this study can supplement existing teaching practices used in the teaching of mathematics in schools and can carry across to teaching undergraduate courses.

\section{INTRODUCTION}

Understanding statistics is essential for addressing the relative shortfall of adequately skilled individuals for the Big Data age (Manyika et al., 2011), and mathematical skills may be considered a requisite skill. The ability to apply both multivariate and univariate approaches, as well as to effectively use statistical concepts such as multilevel linear regression, random coefficient models, among others, is paramount for the effective analyses of data (Hedeker \& Gibbons, 2006; Snorrason, 2012). Teaching this content, however, is challenging and teaching the next generation requires suitable teaching practices to motivate and better support learners (Howley, 2008; Stojanovski, 2015a). However, the attitudes of students towards statistics subjects can be negative as students can lack engagement with statistics (Howley, 2008; Howley, 2009; Stojanovski, 2015b). This can be due to the quality of previous exposure to statistics or mathematics in school and having poor mathematics foundations.

There is an increased need to develop teaching practices to achieve positive outcomes in statistics education. Improved mathematics teaching in schools is essential with the intention to motivate more students to undertake Science, Technology, Engineering and Mathematics (STEM)related courses at University given the demand for analysts (Manyika et al, 2011). Effective teaching is also integral in providing the required knowledge and skills in statistics.

An examination of teaching practices that instructors employ and their effects in terms of support and motivation to learners is essential (Lamy and Steve, 2016). For the present study, an assessment of mathematics teaching practices in relation to mathematics performance is conducted. The relationship between students' anxiety and math performance is also examined as it has been identified that anxiety towards mathematics is an important barrier that limits students undertaking further studies in mathematics post-secondary schooling (Tyson et al., 2007; Winkelman, 2009).

\section{METHODOLOGY}

Data from 10,966 secondary school students participating in the Programme for International Student Assessment (PISA) 2012 study in Qatar were analysed. The PISA measures the performance of 15 year olds in reading, mathematics, and science literacy (OECD, 2013). Various measures were also collected at the student level relating to demographics (including measures of socio economic status and parents' education levels) as well as measures that impact on the capacity of students to learn (such as different teaching strategies) (OECD, 2013). Teaching strategies used for teaching mathematics were assessed in terms of mathematics exam performance to determine whether teaching strategies have an effect on performance in this population. Mathematics exam performance was measured using a score out of 35 representing the proportion of administered questions that were answered correctly. Final scores were standardised. Demographic information was also collected including measures such as the highest education levels (measured on a scale from 0-6 ranging from no formal education to postgraduate qualifications) of the students' mother and father and a measure of socio-economic status which 
was made up of items pertaining to quality of living standards (a higher measure indicated a higher socio-economic status).

Nine teaching strategies were assessed. Each strategy is measured using a subscale comprising several items, which was administered to students as part of a student questionnaire. A brief description of each teaching strategy follows. Attributions to Fail: is a measure of the quality of teacher explanation and ability of teacher to keep students engaged; Maths Teaching: measures teacher interest and provision of additional help; Teacher support: encourages hard working students with provision of additional help. Formative Assessment: provides feedback for improvement of work; Teacher-Directed Instructions: measures clarity and understanding of learning goals; Student Orientation: measures assignment of complex projects and encourages group work. Cognitive Activation: encourages reflections of problems, presents problems in different contexts requiring students to think and encourages learning from mistakes, applying learnt material. Disciplinary Climate: a focus on discipline and a measure of disorder in classroom; Student-Teacher Relations: fair teacher listens to students.

Multilevel models were applied as data were collected for the PISA study at the student level within a sample of schools from the population of schools in Qatar. Multilevel models permit the existence of hierarchies in the data, here school level data, recognising the possibility that students within a school are likely to be more highly correlated compared with the correlation between students from different schools. As such, schools were identified in the models as random effects. These models were used to assess the relationship between: teaching strategies and mathematics performance score.

\section{RESULTS}

The results of fitting the model of each teaching subscale separately against math exam performance demonstrated that each of the ten teaching strategies were significantly related to exam performance. To test for potential multicollinearity between the teaching subscale measures, correlations between teaching strategy subscales were assessed. All correlations were of magnitude 0.6 or less, indicating that multicollinearity was not of major concern for the proposed analyses. All subscales were consequently considered for inclusion in the adjusted model as predictors. The result of including all subscales as predictors with exam performance as the outcome is displayed in Table 1.

Table 1. Model with Math Performance score as outcome and each teaching strategy as predictors.

\begin{tabular}{|l|c|c|c|}
\hline \multicolumn{1}{|c|}{ Effect } & Estimate & $\begin{array}{c}\text { Standard } \\
\text { Error }\end{array}$ & P-value \\
\hline Intercept & 0.20 & 0.02 & 0.02 \\
Attributions to Fail & 0.10 & 0.01 & 0.46 \\
Teacher Directed & 0.02 & 0.0002 & 0.02 \\
Maths Teaching & 0.10 & 0.01 & 0.39 \\
Student Orientation & -0.04 & 0.0004 & 0.01 \\
Formative Assessment & -0.01 & 0.0001 & 0.01 \\
Cognitive Activation & 0.02 & 0.0002 & 0.02 \\
Teacher Support & 0.01 & 0.0001 & 0.03 \\
Disciplinary Climate & 0.01 & 0.0001 & 0.01 \\
Student Teacher Relations & 0.01 & 0.0001 & 0.02 \\
\hline
\end{tabular}

After adjusting for all the teaching strategies, the strategies that remained statistically significant were considered within a reduced model, the results of which are reported in Table 2. 
Table 2. Reduced Model with Math Performance score as the outcome and the reduced set of teaching strategies as the predictors.

\begin{tabular}{|l|c|c|c|}
\hline \multicolumn{1}{|c|}{ Effect } & Estimate & $\begin{array}{c}\text { Standard } \\
\text { Error }\end{array}$ & P value \\
\hline Intercept & 0.18 & 0.01 & $<0.01$ \\
Teacher Directed & 0.02 & 0.0002 & $<0.01$ \\
Student Orientation & -0.04 & 0.0001 & $<0.01$ \\
Formative Assessment & -0.00 & 0.001 & 0.32 \\
Cognitive Activation & 0.02 & 0.001 & $<0.01$ \\
Teacher Support & 0.01 & 0.0001 & $<0.01$ \\
Disciplinary Climate & 0.02 & 0.0001 & $<0.01$ \\
Student Teacher Relations & 0.01 & 0.0001 & 0.08 \\
\hline
\end{tabular}

Teacher Directed instructions, Student Orientation, Cognitive Activation, Disciplinary Climate, and Teacher Support remain statistically significant predictors of exam performance in this reduced model while Formative assessment and Student Teacher Relations are no longer significant predictors of exam performance and as a result were removed from the model.

As further adjustment variables, socio economic status and parent's education level are also considered as additional predictor variables in the model as it is well recognised that these are important predictors of school student's success in education. All teaching subscales remain statistically significant $(\mathrm{p}<0.01)$ and level of mother and father education are also statistically significant predictors of math score $(\mathrm{p}=0.004$ and $<0.001$ respectively) with higher scores indicating a higher math exam performance score. However, socio economic status is not significant $(\mathrm{p}=0.08)$.

\section{CONCLUSION}

In summary, students performed better when teacher-directed instructions were provided, when student orientation was the focus and when cognitive activation was used. All share important characteristics of the steer towards cognitive based approaches to teaching mathematics. Disciplinary teaching approaches were also significant, although the effect was not as strong compared with the other cognitive approaches to teaching. While the notion of cognitive learning strategies leading to improved math performance is supported, there is a need for further scrutiny on how the teaching component may be balanced out with other teaching approaches to enhance student performances in mathematics. The generalisability of the results is however limited by the country-specific nature of the data employed.

\section{REFERENCES}

Hedeker, D., \& Gibbons, R. D. (2006). Longitudinal Data Analysis. Hoboken, NJ: Wiley.

Howley, P. P. (2008). Keeping it real, keeping them interested and keeping it in their minds. Journal of Statistics Education, 16(1).

Howley, P. P. (2009). Winning them over. In David Allingham (Ed.), ASEARC: Proceedings of the Third Annual ASEARC Research Conference, (pp. 1-4). Wollongong, NSW: Applied Statistics Education and Research Collaboration (ASEARC). Online at http://www.uow.edu.au/informatics/maths/research/groups/asearc/2009rescon/index.html

Lamy, M., \& Steve M. (2016), Why Students Are Motivated To Learn Maths, PISA 2012: Series on Learners, 3, 10-20.

Manyika, J., Chui, M., Brown, B., Bughin, J., Dobbs, R., Roxburgh, C., \& Byers, A. H. (2011). Big data: The next frontier for innovation, competition, and productivity. McKinsey Global Institute. Retrieved May 25 2017, from http://www.mckinsey.com/business-functions/digitalmckinsey/our-insights/big-data-the-next-frontier-for-innovation

OECD. (2013). PISA 2012 Assessment and Analytical Framework: Mathematics, Reading, Science, Problem Solving and Financial Literacy. OECD Publishing, 13-20. 
Snorrason, S.T. (2012). Asymmetric Economic Integration: Size Characteristics of Economies, Trade Costs and Welfare. London, England: Springer.

Stojanovski, E. (2015a). Adjusted Pedagogy for Teaching Statistics. PEOPLE: International Journal of Social Sciences, Special Issue 169-177.

Stojanovski, E. (2015b). Interdisciplinary Teaching of Statistics, 21st International Congress on Modelling and Simulation (MODSIM), 1979-1982.

Tyson, W., Lee, R., Borman, K.M., \& Hanson, M.A. (2007). Science, technology, engineering, and mathematics (STEM) pathways: High school science and math coursework and postsecondary degree attainment. Journal of Education for Students Placed at Risk, 12(3), 243

Winkelman, P. (2009). Perceptions of Mathematics in Engineering. European Journal of Engineering Education, 34(4), 305-316. 